\title{
The Relationship Between Work Integrity and Other Variables and Behaviors
}

\author{
Tereza Př́hodová1,2,3 (D), Marek Preiss ${ }^{1,3}$ (D), Radek Heissler ${ }^{1}$ (D), Eva Straková ${ }^{1}$ (D), \\ Edel M. Sanders ${ }^{3}$ (D), Pavel Harsa² (iD) \\ ${ }^{1}$ Psychology department, National Institute of Mental Health, Klecany, Czech Republic \\ ${ }^{2}$ Department of Psychiatry, 1st Faculty of Medicine, Charles University, Prague, Czech Republic \\ ${ }^{3}$ Psychology Department, University of New York in Prague, Prague, Czech Republic
}

\begin{abstract}
The purpose of this study was to examine the work integrity relationship between behaviors directly influenced by integrity of employers and employees, and variables that may enhance or hinder the integrity levels in the relationships between industrial and organizational psychology. The study included one sample of 121 participants tested in the Czech Republic, using an integrity test, personality tests, morality assessments, a social desirability scale, and tests focusing on undesirable and deviant work behaviors. The linear regression model proposed significant predictors of integrity with a positive effect: work years, Openness to new experiences, Conscientiousness, and Impression management, thus representing enhancing integrity factors. Non-clinical psychopathy was found to be the only significant predictor of a negative effect, hence demonstrating a hindering integrity factor. Although integrity predicts work-related undesirable behavior and moral disengagement, testing during the recruitment process is costly. Our findings illustrate a set of variables that enhance or hinder integrity levels. Therefore, this study may provide alternative means for measuring or re-evaluating integrity test results.
\end{abstract}

Key words: work integrity, counterproductive work behavior, working population, personnel selection

\section{Introduction}

Literature provides us with different definitions of integrity. The term "integrity" comes from the Latin word "integer", which may be translated as wholeness. Interpretations con- sistently describe it as wholeness, inviolability, and integrity of all personality structures and functions (Cakirpaloglu, 2012) and conceive integrity as one of the basic characteristics of a mentally healthy personality (Hartl \& Hartlová, 2010). Furthermore, positive psychology approaches integrity as a character asset and

Correspondence concerning this article should be addressed to Tereza Príhodová, Psychology department, National Institute of Mental Health, Topolová 748, Klecany, 250 67, Czech Republic.

E-mail: tereza.prihodova@nudz.cz 
a universal value respected by various people over time (Peterson \& Seligman, 2004). One philosophical perspective approaches integrity primarily from the relationship to oneself (Williams, 1981). Sometimes honesty, credibility, reliability, conscientiousness, or persistence are also cited as alternative concepts of integrity (Preiss et al., 2014). The dominant concept is the perception of integrity as a higher-order factor including conscientiousness, friendliness, and emotional stability (Ones et al., 1993; van der Linden, te Nijenhuis, \& Bakker, 2010).

This approach is very closely related to the focus of this article, which emphasizes industrial and organizational psychology and its approach to integrity in a more practical way. Work and behavioral psychology (Cribb, 2011) conceptualize integrity as behavior, which balances levels of obedience with one's own moral compass. Work positions and daily routines may create moral stresses, tensions, or dilemmas, despite the fact that some people may not perceive them as such. These dilemmas or conflicts need to be handled by the employee and, thus, might be observed and evaluated by the psychologists, employers, or other specialists in the field (Cribb, 2011). Regardless of the anchoring of integrity within the tradition of moral relativism, these conflicts may be handled differently depending on the individual people, culture, or era (Parry \& Proctor-Thomson, 2002). Therefore, when testing integrity at the workplace or elsewhere, attention needs to be paid to the tradition and should take into consideration the condition within which the testing takes place.

The approach of the presented study of work integrity considers the routine moral burden of occupying a professional role and having to negotiate tensions between the normative expectations attached to that role and one's own personal moral compass (Cribb,
2011). However, as it would be methodologically strenuous to capture such an abstract concept including moral stresses, tensions or dilemmas, it also incorporates for psychometrical purposes the concept introduced by Bennett and Robinson (2000). Bennett and Robinson's (2000) concept of counterproductive work behavior is defined as a voluntary behavior, which significantly violates organizational standards and threatens the well-being of the organization or its members or both. This concept allows researchers to psychometrically measure the abstract concept of work integrity, by defining it in terms of harmful behaviors (Robinson \& Greenberg, 1998). The general acceptance of harmful behavior relating to counterproductive work behavior resides in a failure to respect social and organizational rules and values (Raman, Sambasivan, \& Kuman, 2016), which may be detected by integrity tests. Moreover, beneficial inclusion, as it was studied in relation to integrity in the presented integrity model, was an addition to the counterproductive work behavior concept.

\section{Integrity and its Relation to Behavior that could be Costly to Employers}

Integrity measures were developed to predict problematic behaviors, including thefts, frauds, absences, unauthorized compensations, determination of non-productive work behaviors, or disobeying work regulations (Ones \& Viswesvaran, 2001), which may lead to increased costs to the employer. Some work integrity tests are still predominantly designed to reveal more information about the responsibility, moral integrity, and honesty of applicants. Although the original purpose of predicting thefts and other dishonest behaviors remains the core concept (Ones \& Viswesvaran, 2001), the incorporation of integrity tests into the work assessment pro- 
cess revealed that employees, who have been working for the company less than one year were in a high-risk position for suspicious compensation claims. Based on the last 85 years of research, the best predictors for successful hiring processes are (aside from previous work experiences) conscientiousness, personal integrity, job knowledge, and variables commonly labeled as general mental ability (Schmidt \& Hunter, 1998). The popularity of these tests is on the rise, while the majority are still predominantly administered in the USA (Sackett \& Harris, 1984; Oliver et al., 2012).

A comprehensive study was performed by Oliver et al. (2012), in which four industrial groups of job applicants were examined via integrity tests. In this study, researchers included compared screened and unscreened employees of an car club, nursing home, food processing company and multimedia company, who were tested using the Tescor Survey. The Tescor Survey is an overt integrity test targeting risk assessment connected to accident claim cost, while including four scales (theft, substance abuse, hostility, and faking). Compensation claims were evaluated based on the information disclosed by each company, including also the costs associated with them. The screened group was composed of new employees, who were tested during the hiring process, and they were hired only if they passed the integrity assessment, while no other check of the validity of the data (e.g., urine tests, criminal history checks) was done. The unscreened group included long-time employees. The researchers then compared the workplace injuries compensation claims collected from the insurance brokers. Results showed that the number of employee's compensation claims and their costs were lower in the screened group. Particularly, for the nursing home chain in the unscreened group, $10.0 \%$ of employees filed for compensation, while in the screened group, this compensation was filed by only $2.2 \%$ of the employees. Similar findings were also found for the food processing company, where the ratio was $6.6 \%$ to $3.2 \%$, or the car club, where the ratio was found to be $7.0 \%$ to $1.6 \%$, and for the multimedia company $5.7 \%$ to $3.6 \%$. These percentages translate to the following differences in the average costs per employee: for the nursing home chain it was $\$ 212$ compared to $\$ 27$, the car club $\$ 323$ compared to $\$ 50$, the food processing company $\$ 206$ compared to $\$ 77$ and the multimedia company \$309 compared to $\$ 56$.

Oliver et al.'s (2012) study has shown that the inclusion of integrity tests during the hiring process has the potential of enhancing safer workplaces and lowering the companies' costs associated with injury compensation claims. On the other hand, economists may argue that integrity tests are often criticized for their high price, which was the focus of the Sturman and Sherwyn (2007) study. The study attempted to show that in spite of the high cost of integrity tests, the savings due to the detection of integrity problems were high, the immediate profit for one of the companies that was included in their study was $\$ 135,673$ and the return investment was $5 \%$.

\section{Integrity as a Potential Predictor of Behavior}

Based on the findings of the studies above, the level of integrity seems to have influence over or even predict some types of behaviors at the workplace (Oliver et al., 2012; Ones \& Viswesvaran, 2001; Schmidt \& Hunter, 1998). Lucas and Friedrich (2005) reported that academic dishonesty and workplace theft may be predicted by the level of integrity. These findings have been supported by Martin et al. (2009), who suggested that a higher level of integrity is associated with a lower tendency towards plagiarism and lower tendency to 
engage in white-collar crime. Prottas (2008) measured managerial behavioral integrity at the workplace, which showed a positive relationship with satisfaction at work and a negative relationship with stress, poor health condition, and absenteeism. Other behaviors influenced by integrity include job performance (Luther, 2000; Ones et al., 1993), job satisfaction (Mount et al., 2006; Prottas, 2008) and well-being (Prottas, 2008).

Previous studies also identified moral disengagement as work-related behavior that may be influenced by the level of individual integrity (Moore et al., 2012; Duffy et al., 2005). Albert Bandura belongs to the group of founders, who examined the concept of moral disengagement, which was introduced as an extension of his more general social cognitive theory (Bandura, 1991). Based on Bandura's conceptualization, there are eight mechanisms of moral disengagement characterized as a coherent set of cognitive tendencies influencing one's approach in decisions of ethical significance. Some studies have followed up on the topic and tried to measure this concept using various techniques (Vrbová, 2014; Moore et al., 2012). In adults, a detailed analysis was done by Moore et al. (2012), who presented a higher-order concept, tapping each of the eight specific mechanisms. Moore et al.'s (2012) study showed that propensity to moral disengagement is capable of predicting several antecedents, providing relevant premises for the study of the relationship between integrity and moral disengagement.

\section{Variables as Potential Predictors of Integrity}

Since previous studies have shown an evidence for the influence integrity may have on workplace behaviors, it would also be beneficial to target variables, which may enhance or hinder work integrity levels. The reason for targeting those variables is that integrity tests may not always be accessible to researchers or specialists in the hiring process. One of the reasons might be their cost, another could be simply because they are not part of the general practice in a particular region, such as in the Czech Republic. The detection of variables that are potential predictors of integrity could provide at least a general precursor of individual personal integrity.

One of the simplest variables that could be tested are demographic and personality variables. These variables were previously tested by Ones and Viswesvaran (1998a), who studied gender, age and race influence. This study did not reveal substantial differences in integrity levels based on race or gender-age interaction. Only small differences were found between younger and older applicants. Studies focusing on the relationship between integrity and personality traits differ in their findings, depending on the personality theory chosen. For example, studies using the Big Five theory revealed a strong direct negative correlation between Agreeableness and Conscientiousness and counterproductive work behavior, even when job satisfaction was taken as a mediating factor (Mount et al., 2006). Other studies looked at the Dark Triad theory of personality and revealed that each of the three traits is related to unethical work behaviors, hence with integrity. Jonason et al. (2012) found that threats were associated with Psychopathy, direct manipulation together with charm related to Machiavellianism, and Narcissism was linked to appearance. Similarly, O'Boyle et al. (2012) found a moderate amount of variance of counterproductive work behavior explained by Dark Triad traits.

Next, Coyne and Bartram (2002) suggested that social desirability should be controlled for when assessing integrity or undesirable behavior, as it may by large influence the validity of the assessment. Similar results were also found in the Jansen et al.'s (2012) study, 
which suggested that social desirability is associated with strategic self-representational behaviors associated with situational requirements. Finally, moral values are another concept that was revealed by the previous studies as one potential factor influencing integrity. Moral values generally refer to the extent to which one possesses internalized and stable values and morals of his or her inner experience guiding behavior. Such an abstract construct may be measured using different techniques. For example, by using moral reasoning abilities (Moore et al., 2012) or by studying the level of moral identity (Black \& Reynold, 2016).

\section{Current Study}

The current study focused on work integrity including specific behaviors that it may influence, while also providing a set of variables that may hinder or enhance the level of work integrity in a working population. These behaviors and variables were detected based on a comprehensive literature review, in order to capture those that are frequently presented or assessed. Therefore, the current study aimed to provide a more extensive and comprehensive approach based on previous studies focusing on the working population in the Czech Republic (Šamánková, Preiss, \& Př́hodová, 2018), connecting and re-evaluating findings on moral disengagement (Moore et al., 2012), cheating (Lucas \& Friedrich, 2005) and work deviance (Bennett \& Robinson, 2000). The chosen variables enhancing or hindering integrity included demographic variables (Ones \& Viswesvaran, 1998a), personality traits (Mount et al., 2006; Jansen et al., 2012), social desirability (Coyne \& Bartram, 2002) and moral values (Black \& Reynold, 2016). Thus, the study had three goals: first, to evaluate the influence of demographic variables such as age and health status, per- sonality traits, social desirability, and moral values on integrity, as they seem to be variables influencing work integrity; second, to evaluate the influence of integrity on moral disengagement mechanisms and work-related undesirable or unethical behavior; finally, the third aim of the study was to construct an integrity model displaying variables that may enhance or hinder integrity and behaviors, which would be influenced by integrity. This model was prepared based on the variables targeted by previous studies in the introduction and then based on the statistical analysis of the working sample used in this study.

\section{Materials and Methods}

\section{Ethical Standards}

This study was carried out in accordance with the recommendations of the National Institute of Mental Health ethics committee with written informed consent from all individuals in accordance with the Declaration of Helsinki. All gathered data were handled confidentially, and each participant's identity was kept strictly anonymous.

\section{Participants}

The presented study was performed on a group of participants from the general population that was collected at various workplaces. The study included 121 individuals with the average age of 39.21 years $(S D=14.44)$; the gender distribution was slightly skewed, $41.32 \%$ were male. In terms of education, a majority of the sample (70.25\%) had secondary education, $5.78 \%$ held a primary degree, $23.97 \%$ had a university degree. The majority of the participants currently worked full-time or had been employed full-time for a substantial time; the average number of years of fulltime employment was 18.78 (SD = 14.39). The 
working sample represented a wide range of different professions including laundresses, housekeepers, chefs, and assembly or construction workers, while also including lawyers, legal assistants, financial specialists, and legal trainees. Given the wide range of jobs, profession was controlled for during the statistical analysis.

The sampling method used was opportunistic, and participants were recruited using convenience sampling. The inclusion criteria consisted of the minimum age of 18 , current active employment status or an active employment status for a substantial time of their working career, and willingness to participate. The exclusion criteria included having a retirement pension, alcohol or drug dependence or abuse in the last 12 months prior to the inclusion into the project, and any mental or neurodegenerative disorders.

No participants were excluded from the study. At the beginning, participants were handed the document Information for participants, explaining the purpose of the study and the procedure. Then they were asked to sign an informed consent form, which was stored separately from the collected data. Participation in the study was completely voluntary and participants could withdraw their consent to participate at any time during the testing or at the end. No participant chose to withdraw their consent. All of the instruments were collected using pen and paper versions. All of the questionnaires were administered to the participants at the same time in one setting in the same order, as there was no assumption of order effect. All individuals, regardless of their performance, received a financial reward for their participation of $300 \mathrm{CZK}$.

\section{Methods}

This study included several questionnaire methods to capture the influence of per- sonality traits, social desirability, and moral standards on integrity. The second cluster of self-reports included methods focusing on behaviors that may be influenced by personal work integrity levels. The selection of the specific methods was based on good psychometric properties, availability of the questionnaires during the data collection, and administration time needed. All of these methods include variables and behaviors described to have a relationship to integrity, as mentioned in the Introduction, corresponding with aims of the study.

Integrity Test. The integrity test we used evaluated the overall integrity level. The overall integrity score corresponds with a combination of work and personal integrity, which is applicable in working environments. The test was created and administered in the Czech Republic (Příhodová et al., unpublished manuscript); its construction was based on previous studies carried out by Bennett and Robinson (2000). The psychometric properties showed good internal consistency, measured by stratified Cronbach's alpha of overall integrity ( $\alpha=.866$; Príhodová et al., unpublished manuscript). The use and applicability of the test had already been established in previous studies (Př́hodová et al., 2017; Preiss \& Př́hodová, 2017; Raisová et al., 2019). The measure is composed of 32 items, where participants rate each item on a 5-point Likert type scale, ranging from 1 (strongly disagree) to 5 (strongly agree). Exemplary items are: "During working hours, I work on things that are not related to my work" or "I would always confess to my mistake at work." A higher score on the scale indicates higher levels of integrity.

Balanced Inventory of Desirable Responding (BIDR-CZ). This measure was originally developed by Paulhus (1984) and adapted by Preiss and Mačudová (2013). It was included in the study to measure one of the antecedents of 
integrity, particularly the level of social desirability. The 40 items feed the Self-deception (SDE) scale (Paulhus, 1984) measuring the honest responding style, disrupted by the unconscious improvement of self-image. The Impression Management (IM) scale (Paulhus, 1984) assesses the respondent's conscious effort to present him/herself in a socially desirable way (Preiss \& Mačudová, 2013). Items are scored on a 7-point Likert type scale, ranging from 1 (strongly disagree) to 7 (strongly agree); higher scores indicate a higher tendency towards social desirability. The psychometric properties of the adapted version showed good internal consistency ( $\alpha$ : SDE $=$ $.70, \mathrm{IM}=.80)$.

The Big Five Inventory (BFI-44). The BFI-44 is a 44-item self-report, originally developed by John et al. (2008), and adapted by Hřebíčková et al. (2016). It was included into the study for the evaluation of personality traits, which may influence the individual level of integrity, and because of its good psychometric properties, indicated by the levels of internal consistencies (Cronbach's $\alpha$ : Extraversion $=.81$, Agreeableness $=.68$, Conscientiousness $=.79$, Neuroticism $=.83$ and Openness $=.75$ ). The five scales are evaluated on a 5-point Likert type scoring, higher scores indicate higher levels of such personality characteristics.

The Short Dark Triad (SD3). The second measure evaluating personality and its influence on integrity that was chosen was the SD3. This method measures undesirable personal characteristics and was originally developed by Jones and Paulhus (2014). The questionnaire consists of 27 items, evaluated on a 5-point Likert type scale ranging from 1 (strongly disagree) to 5 (strongly agree). Items saturate non-clinical scales of Machiavellianism, Narcissism, and Psychopathy, while higher scores indicate accentuated personal characteristics. The translated version of the questionnaire showed good internal consis- tency values (Cronbach's $\alpha$ : Machiavellianism $=.71$, Narcissism = .74, Psychopathy = .77; Mejzlíková et al., 2018).

General Health Questionnaire (GHQ). GHQ was originally introduced by Goldberg and Blackwell (1970) and translated by Škoda et al. (1994). The measure was included in this study to evaluate the influence of health status on integrity. The original questionnaire consists of 60 items, shorter versions consist of $30,28,20$, and 12 items. The 12-item version was used for this study for time reasons. Each item rates a current state of an individual on a 4-point scale. There are two types of scoring that are used interchangeably, the bi-modal scoring (used in this study) is 0-0-11. In either of the scoring systems, a higher score corresponds with the higher level of subjective pathology.

Schwartz Outcome Scale - 10 (SOS-10). This 10-item questionnaire focuses on an individual's global psychological functioning and well-being, which is further connected to health status. It was included in order to evaluate whether well-being would show a different relationship to integrity as opposed to general health status. The original method was developed by Blais et al. (1999) and translated by Dragomirecká et al. (2006) and showed good psychometric properties (Cronbach's $\alpha=.92$ ). Each item is answered on a 7-point Likert type scale, ranging from 0 (not accepted at all) to 6 (strongly accepted); a better perception of one's psychological state corresponds with higher scores.

The Measure of Moral Identity (MI). The measure of moral identity originally developed by Aquino and Reed (2002) presents a 13-item self-report evaluating an individual's sets of moral characteristics. This measure was chosen for the study to evaluate the level of personal moral identity and its influence on integrity. The measure focuses on internalization, describing how important moral charac- 
teristics are for one's own conscience, while the symbolization score presents extroversion connected with moral values put on display. The translated version showed similar levels of internal consistency ( $\alpha=.79$ internalization, .83 symbolization) (Juríčková et al., 2020). Each participant is presented with 9 traits evaluated as moral and are asked to imagine a person with all of these characteristics, then to answer items on a 7-point Likert type scale regarding such person. Higher scores indicate higher levels of internal moral identity and a higher tendency to present it to the world.

Propensity to Morally Disengage Scale (MD). The tendency towards moral disengagement was assessed using the Propensity to Morally Disengage Scale (Moore et al., 2012). This measure focuses on adults and is applicable to working populations. It was chosen to evaluate the influence integrity may have on the tendency towards moral disengagement. The original scale showed internal consistency evaluated by Cronbach's $\alpha$ of .90 (Moore et al., 2012), comparable to the translated version, Cronbach's $\alpha$ was .91 (Příhodová et al., manuscript under review). The 24 items are scored on a 7-point Likert type scale, ranging from 1 (strongly agree) to 7 (strongly disagree) saturating 8 moral disengagement mechanisms. Higher scores indicate a higher tendency to engage in a specific mechanism of moral disengagement.

Cheating at Work Scale (CWS). This questionnaire was originally developed by Sims (1993). Current version used is the combination of Sims (1993) and adapted version of a questionnaire from Hilbert (1985) study. The reason for the inclusion of this measure was to evaluate the influence integrity may have on undesirable work behavior. The translated version showed good psychometric properties (Cronbach's $\alpha$ for Attitude to cheating $=.91$, Perception of cheating $=.84$ ). The 21 items are answered by the respondent twice, in order to saturate Attitude to cheating and Perception of cheating. Cheating attitude is rated on a 4-point Likert scale ranging from 1 (definitely cheating) to 4 (not cheating at all), the Perception to cheating is rated on a 5-point Likert scale ranging from 1 (never) to 5 (very often). The main goal is to measure the attitude towards and perception of dishonest behavior at work; higher scores indicate higher tolerance and tendency to engage in such behavior.

Unethical Work Behavior Scale (UWBS). The scale evaluates the tendency towards counterproductive work behavior and was chosen to evaluate the influence of integrity on it. This 19-item questionnaire was originally developed by Robinson and O'Leary-Kelly (1998) and Bennett and Robinson (2000). The translated version of this measure showed good psychometric properties (Cronbach's $\alpha$ of interpersonal scale $=.85$, organizational scale $=.83$ ). Items are rated on a 7-point Likert scale ranging from 1 (never) to 7 (every day). A higher score represents a higher tendency towards counterproductive work behavior.

\section{Data Analysis}

Statistical analyses included descriptive statistics, between-group comparisons, correlations, and a linear regression model. Data were processed in the $\mathrm{R}$ software environment (R Core Team, 2016) and JASP v. 0.11.1.

Testing for normality of scores distribution was done with the Shapiro-Wilk test. As most of the scores were not normally distributed, non-parametric tests were used in further analyses: Spearman's $\rho$ for correlations of the Integrity score, all other tests and relevant demographics. Kruskal-Wallis $H$ test (effect size measured by epsilon-squared $\varepsilon^{2}$ ) and Mann-Whitney $U$ test (effect size is given by the rank biserial correlation $r_{r b}$ ) were used to analyze differences between categorical vari- 
ables (gender, education) and the total Integrity score. Multivariate linear regression analyzed the relationship between the Integrity test and other relevant tests and variables to determine the theoretical model of work integrity, and also its influence on work-related undesirable or unethical behavior, or moral disengagement mechanisms.

\section{Results}

Tables 1, 2 and 3 in the Supplement summarize the descriptive statistics of all recorded demographic variables and results of all administered tests for the entire sample. We have analyzed the relationship of the Integrity test with all scales and demographic variables of the whole sample. There were no differences in the Integrity scores in gender $(U=$ 1492; $\left.p=.14 ; r_{r b}=-.16\right)$, and education $\left(\chi^{2}=\right.$ 4.6; $\left.\mathrm{df}=2 ; p=.1 ; \varepsilon^{2}=.038\right)$. Spearman correlations were statistically significant for age $(\rho=.45 ; p<.001)$, and work years $(\rho=.47 ; p<$ .001). Results of the Spearman correlations of the Integrity test and all other scales used are shown in the Supplement in Table 4. Correlations were statistically significant for all variables measured in SD3, Impression management in BIDR-CZ, SOS-10, variables assessed by $\mathrm{BFI}-44$ except Extraversion, and all moral disengagement mechanisms (except Dehumanization), both scales of CWS, and UWBS.

Of those variables, prior to the construction of the regression model for Integrity, we have selected those significantly correlated with the Integrity score $(p<.05)$ that we assumed, based on the research stated in the introduction, to precede integrity - i.e., age, work years, job classification (mainly manual/ physical labor, or mainly office and administrative setting), all measures in SD3, IM in BIDR-CZ, SOS-10, and all dimensions of BFI44 except Extraversion. When these variables were entered as predictors of Integrity in the linear regression model (Backward elimination method), the final model showed that the best predictors of Integrity were: work years, Openness to new experiences, Conscientiousness (BFI-44), Impression management (BIDR-CZ), all with a positive effect, and non-clinical Psychopathy (SD3) with a negative effect. There was a significant effect of the above-mentioned variables: $F(5,115)=$ 24.95, $p<.001, \operatorname{AdjR}^{2}=.5$. The model fits the requirement of normal distribution of residuals ( $\mathrm{W}=.99, p=.31$ ), no multicollinearity (VIF range 1.16-1.92), as well as absence of their autocorrelation ( $D W=2, p=.98$ ). Table 5 shows the results of the initial and the final model.

The estimated regression equation for integrity is: $f$ (Integrity) $=84.25+.24 *$ work years $+5.89 *$ Conscientiousness (BFI-44) + 2.96* Openness (BFI-44) + .29*IM (BIDR-CZ) - .62*Psychopathy (SD3).

Afterwards, the Integrity score was analyzed as a predictor measure with an influence on work-related undesirable behavior or moral disengagement mechanisms, as was supported by the research studies mentioned in the introduction; specific measures of MD, CWS, and UWBS were applied. The results are presented in Table 6. As models did not pass the Shapiro-Wilk test for normality of residuals distribution, results of models with rank-transformed data (Rankit transformation suggested by Soloman \& Sawilowsky, 2009) are also shown.

\section{Discussion}

The first aim of the study, leading towards the construction of the integrity model, was to evaluate the influence of demographic variables including age and health status, personality traits, social desirability, and moral values on integrity. Results showed no differences in regards to gender and education, 
which might suggest integrity being a trait-like variable, not influenced by the level of education or job type, which was controlled for, or gender.

Health status was shown to be in a significant positive relationship with integrity yet did not enter the final model. This finding is supported and extended by previous findings by Prottas (2008), suggesting a relationship between behavioral integrity and poor health condition in a purely managerial sample. This study advanced these findings to the working population in general. The two demographic variables that showed a significant correlation with integrity were age and work years, while the linear regression model showed that the strongest antecedent of integrity was work years, representing an enhancing integrity factor. This suggests that age did not play as significant a role, which is in line with the original expectation, as we are dealing specifically with working integrity. These results extended the findings of the Ones and Viswevaran (1998a) study, that revealed only small differences between younger and older applicants. The interpretation for both variables may reside in the interplay between integrity and integration. Higher age and correspondingly more working years could relate to a more mature and sophisticated personality structure, which may be achieved through ontogeny.

In terms of personality traits, results suggested a relationship between integrity and non-clinical Narcissism, Psychopathy, Machiavellianism, and all characteristics assessed by BFI-44 except Extraversion. The linear regression model found a negative effect of non-clinical Psychopathy on integrity. Psychopathy was the only aspect of the Dark Triad personality traits entering the model, representing a hindering integrity factor. In this context, psychopathy is characterized by ongoing antisocial behavior, impulsivity, low em- pathy, and manipulation (Paulhus \& Williams, 2002). This finding supported the Ashton et al. (2000) study, in which similarly strong correlations were found among all Dark Triad characteristics with honesty, described along the lines of integrity or trustworthiness. Further, that study showed an even stronger relationship between Psychopathy and honesty, compared to any Big Five variables (Ashton et al., 2000), which corresponds with the results of our study. Big Five personality variables in the presented study were assessed by the BFI-44, which took precedence over other methods evaluating personality, such as HEXACO (Lee \& Ashton, 2004). This was mainly due to time constraints and the availability of the measure at the time of data collection. The strongest relationship in terms of Big Five personality theory was found between Agreeableness and Conscientiousness, followed by Openness to new experiences, while the last two mentioned showed a positive effect on integrity, representing enhancing integrity factors. The positive effect suggests that these personal attributes promote higher work integrity and thus could also be searched for when selecting new employees. Big Five model variables were based on previous studies (Mount et al., 2006; Hogan \& Ones, 1997; Ones \& Viswesvaran, 2001), expected to be in a strong relationship with work integrity and job performance. Findings pertaining to the Big Five variables in the linear regression model supported Mount et al. (2006), suggesting direct relationships among variables with the ability to predict counterproductive work behavior.

Finally, in terms of proposed anteceding variables for integrity, impression management was found to be strongly related and having a positive effect on integrity, hence another integrity enhancing factor. This result suggests a possible mediating effect between work integrity and social desirability, which may be due to the overlap of these constructs. 
The influence of social desirability on integrity tests is one of the major criticisms, despite the established controllability (Coyne \& Bartram, 2002). The predictive abilities of social desirability on job satisfaction, loosely related to work performance and thus work integrity, have been shown in previous studies, e.g., the Ones and Viswesvaran (1998) study.

The second aim of the study was to evaluate the influence of integrity on moral disengagement mechanisms and work-related undesirable or unethical behaviors. Statistical analysis revealed significant relationships to all moral disengagement mechanisms (except Dehumanization), and they were in sum shown to be predicted by the level of integrity, based on the linear regression model. Findings of the present study showed similar results to Moore and colleagues (2012), suggesting a relationship between unethical organizational behavior and moral disengagement mechanisms, providing relevant premises for the study of integrity and moral disengagement. That study further suggested moral disengagement to be an antecedent of undesirable behavior, while the presented study suggests a dual relationship with integrity, placing moral disengagement mechanisms as a consequent. This premise supports previous research by Mobley et al. (2012), concluding that leaders with high ethical standards and resulting high levels of integrity showed a rare tendency towards moral disengagement. In terms of variables relating to cheating and unethical work behavior, both measures showed a significant relationship with integrity and being predicted by integrity. These results add to the growing literature considering the positive relationship between work integrity, and integrity in general, and all different kinds of unethical behaviors (Martin et al., 2009; Lucas \& Friedrich, 2005; Davis \& Rothstein, 2006).

The third aim of the study was to develop a model providing factors enhancing or hinder- ing integrity. At the same time, this model was supposed to capture behaviors that are directly influenced by integrity. This regression model is further described in Tables 5 and 6 and is described in the Results section as well.

\section{Limitations}

The study was limited by a rather small number of participants, mainly due to availability and to a rather lengthy testing procedure. Furthermore, some of the instruments (such as the Moral Identity measure) were culturally sensitive and thus, could have provided skewed information about participants, while reporting no significant relationships. In general, there is a lack of instruments that would assess morality or integrity in the studied culture, and therefore, the variability of the testing methods was limited. Further, the use of HEXACO model instead of the Big Five model could have provided more detailed information and results. Yet, at the time of the data collection, the HEXACO model was not accessible.

\section{Strengths and Future Direction}

One of the strengths of the study was the inclusion of different variables, measurements and statistical methods, which provided multiple aspects of information regarding morality and integrity of the general working population and, therefore, enriched the field of study itself with potentially new perspectives.

In the future, we plan to choose a different combination of the proposed variables and study the deeper processes that could uncover the mechanisms employed in counterproductive work behaviors. The advanced statistical analyses have provided some support for the originally proposed model, and future studies should focus on the underlying processes that strengthen or weaken 
personal and organizational integrity. Finally, integrity tests are not common in the Czech Republic nor across Europe in general. The presented integrity test was developed in the Czech Republic and promises to hold a strong position in the field with enhanced applicability comparable to well-known integrity tests that are currently being used. This conclusion was based on similar results and relationships with various variables provided by supporting studies.

\section{Conclusion}

Originally, integrity tests attempted to predict the possible presence of dishonest behaviors. Recent data pointed towards the increasing trend of administering these assessments during the employee selection process and the associated benefits of these tests (Sturman \& Sherwyn, 2007). Companies are investing more into the hiring process by looking for reliable employees, as they are aware of the cost-benefit analyses. Research in the personnel selection field revealed that integrity tests are among the most reliable and predictive measures of future performance and loyalty administered during the selection process (Casillas et al., 2009). Given the rise and importance of integrity tests, together with their high price, this study also evaluates other factors that may be applied during the integrity assessment process. Results showed that specific personality characteristics, together with social desirability, may provide skewed values of integrity. Additionally, results indicated that there are behaviors that are directly influenced by work integrity, including a tendency towards moral disengagement, cheating and unethical work behavior. These behaviors and other variables have been evaluated in previous studies, however, this is the first study to our knowledge, which combined and analyzed all of the variables in one study and presented them as a unique and comprehensive model.

\section{Acknowledgement}

This study is a result of the research funded by the Czech Science Foundation, grant no. 16-06264S and by the project "Sustainability for the National Institute of Mental Health", under grant number L01611, with a financial support from the Ministry of Education, Youth and Sports of the Czech Republic under the NPU I program, and by the Progres $=C 4=8 D$ . $\mathrm{Q}$ 06/LF1 $=20$.

\section{Authors' ORCID}

Tereza Příhodová

https://orcid.org/0000-0001-9814-6304

Marek Preiss

https://orcid.org/0000-0002-4463-6313

Radek Heissler

https://orcid.org/0000-0003-3165-6216

Eva Straková

https://orcid.org/0000-0002-8225-3719

Edel M. Sanders

https://orcid.org/0000-0001-6462-0127

Pavel Harsa

https://orcid.org/0000-0003-3118-3930

\section{References}

Aquino, K., \& Reed, A. (2002). The self-importance of moral identity. Journal of Personality and Social Psychology, 83, 1423-1440. https://doi. org/10.1037/0022-3514.83.6.1423

Ashton, M. C., Lee, K., \& Son, C. (2000). Honesty as the sixth factor of personality: Correlations with Machiavellianism, primary psychopathy, and social adroitness. European Journal of Personality, 14(4), 359-368. https://doi.org/10.1002/ 1099-0984(200007/08)14:4<359::AID-PER382>3.0.CO;2-Y

Bandura, A. (1991). Handbook of moral behavior and development. New Jersey, LEA.

Black, J. E., \& Reynolds, W.M. (2016). Development, reliability and validity of the Moral Identity 
Questionnaire. Personality and Individual Differences, 97, 120-129. https://doi.org/10.1016/i. paid.2016.03.041

Blais, M. A., Lenderking, W. R., Baer, L., deLorell, A., Peets, K., Leahy, L., \& Burns, C. (1999). Development and initial validation of a brief mental health outcome measure. Journal of Personality Assessment, 3(73), 359-373. https://doi org $/ 10.1207 /$ S15327752JPA7303 5

Bennett, R. J., \& Robinson, S. L. (2000). Development of a measure of workplace deviance. Journal of Applied Psychology, 85(3), 349-360. https://doi.org/10.1037/0021-9010.85.3.349

Casillas, A., Robbins, S., McKinniss, T., Postlethwaite, B., \& Oh, I. S. (2009). Using narrow facets of an integrity test to predict safety: A test validation study. International Journal of Selection and Assessment, 17(1), 119-125. https://doi.org/10.1111/j.14682389.2009.00456.x

Cakirpaloglu, P. (2012). Úvod do psychologie osobnosti. Praha: Grada Publishing.

Coyne, I., \& Bratram, D. (2002). Assessing the effectiveness of integrity tests: A review. International Journal of Technology, 2(1), 15-34. https:// doi.org/10.1207/S15327574IJT0201 2

Cribb, A. (2011). Integrity at work: Managing routine moral stress in professional roles. Nursing Philosophy, 12, 119-127. https://doi.org/10.1111/i.1466769X.2011.00484.x

Davis, A. L., \& Rothstein, H. R. (2006). The effects of the perceived behavioral integrity of managers on employee attitudes: A meta-analysis. Journal of Business Ethics, 67(4), 407-419. https://doi. org/10.1007/s10551-006-9034-4

Dragomirecká, E., Lenderking, W. R., Motlová, L., Goppoldová, E., \& Šelepová, P. (2006). A brief mental health outcomes measure: Translation and validation of the Czech version of the Schwartz Outcomes Scale - 10. Quality of Life Research, 15, 307-312. https://doi.org/10.1007/ s11136-005-1389-y

Duffy, M. K., Aquino, K., Tepper, B. J., Reed, A., \& O'Leary-Kelly, A. (2005). Moral disengagement and social identification: When does being similar results in harm doing? Paper presented at the Academy of Management Annual Conference, Honolulu, Hawaii.

Goldberg, D. P., \& Blackwell, B. (1970). Psychiatric illness in general practice: A detailed study us- ing a new method of case identification. British Medical Journal, 1, 439-443. http://dx.doi. org/10.1136/bmj.2.5707.439

Hartl, P., \& Hartlová, H. (2010). Velký psychologický slovník. Praha, Portál. 800 p. ISBN 978-807368-686-5.

Hilbert, G. A. (1985). Involvement of nursing students in unethical classroom and clinical behaviors. Journal of Professional Nursing, 1(4), 230-234. https:// doi.org/10.1016/S8755-7223(85)80160-5

Hřebíčková, M., Jelínek, M., Blatný, M., Brom, C., Burešová, I., Graf, S., Mejzlíková, T., Vazsonyi, A. T., \& Zábrodská, K. (2016). Big Five Inventory: Základní psychometrické charakteristiky české verze $\mathrm{BFI}-44$ a BFI-10. [Big Five Inventory: Basic psychometric properties of the Czech version of BFI-44 and BFI-10.] Československá psychologie, 6O(6), 567-583. ISSN 0009-062X

Hogan, J., \& Ones, D. S. (1997). Conscientiousness and integrity at work. In Handbook of personality psychology (pp. 849-870). Academic Press.

Jansen, A., Cornelius, J. K., Stadelmann, E. H., \& Kleinmann, M. (2012). Applicant's self-presentational behavior. What do recruiters expect and what do they get? Journal of Personnel Psychology, 11(2), 77-85. https://doi.org/10.1027/1866$\underline{5888 / a 000046}$

JASP Team (2020).

John, O. P., Naumann, L. P., \& Soto, C. J. (2008). Paradigm shift to the integrative Big Five trait taxonomy: History, measurement, and conceptual issues. In O. P. John, R. W. Robbins, P. K. Jonason, S. Slomski, \& J. Partyka (2012). The Dark Triad at work: How toxic employees get their way. Personality and Individual Differences, 52, 449-453. https://doi.org/doi:10.1016/i.paid.2011.11.008

Jones, D. N., \& Paulhus, D. L. (2014). Introducing the Short Dark Triad (SD3): A brief measure of dark personality traits. Assessment, 21(1), 28-41. https://doi.org/10.1177/1073191113514105

Juríčková, V., Babinčák, P., Příhodová, T., \& Preiss, M. (2020). Česká verze škály na měření důležitosti morální identity - pilotní studie. E-psychologie, 4(14), 43-56. https://doi.org/10.29364/ epsy.384

Lee, K., \& Ashton, M. C. (2004). Psychometric properties of the HEXACO personality inventory. Multivariate Behavioural Research, 39, 329-358. https://doi.org/10.1207/s15327906mbr3902 8 
Lucas, G. M., \& Friedrich, J. (2005). Individual differences in workplace deviance and integrity as predictors of academic dishonesty. Ethics \& Behavior, 15(1), 15-35. https://doi.org/10.1207/ s15327019eb1501 2

Luther, N. (2000). Integrity testing and job performance within high performance work teams: A short note. Journal of Business and Psychology, 15(1), 19-25. https://doi.org/10.1023/A:1007762717488

Martin, D. E., Rao, A., \& Sloan, L. R. (2009). Plagiarism, integrity and workplace deviance: A Criterion study. Ethics \& Behavior, 19(1), 36-50. https://doi.org/10.1080/10508420802623666

Mejzlíková, T., Preiss, M., Maliňaková, J., Raisová, M., \& Bolceková, E. (2018). Česká validizační studie škály Krátká temná trojice (Short Dark Triad, SD3). [Czech validation study of the Short Dark Triad (SD3).] Aplikovaná Psychologie (Applied Psychology), 3(5), 255-271.

Mobley, W. H., Wang, Y., \& Li, M. (2012). Advances in global leadership. Bingley: Emerald Group Publishing Limited.

Moore, C., Detert, J. R., Treviňo, L. K., Baker, V. L., \& Mayer, D. M. (2012). Why employees do bad things: Moral disengagement and unethical organizational behavior. Journal of Personnel Psychology, 65, 1-48. https://doi.org/10.1111/ j.1744-6570.2011.01237.x

Mount, M., Ilies, R., \& Johnson, E. (2006). Relationship of personality traits and counterproductive work behaviors: The mediating effects of job satisfaction. Journal of Personnel Psychology, 59, 591-622. https://doi.org/10.1111/i.17446570.2006.00048.X

O’Boyle Jr., E. H., Forsyth, D. R., Banks, G. C., \& McDaniel, M. A. (2012). A meta-analysis of the Dark Triad and work behavior: A social exchange perspective. Journal of Applied Psychology, 97(3), 557-579. https://doi.org/10.1037/a0025679

Ones, D. S., Viswesvaran, C. H., \& Schmidt, F. L. (1993). Comprehensive meta-analysis of integrity test validities: Findings and implications for personnel selection and theories of job performance. Journal of Applied Psychology, 78(4), 679-703. https://doi.org/10.1037/0021$\underline{9010.78 .4 .679}$

Ones, D. S., \& Viswesvaran, C. (1998a). Gender, age and race differences on overt integrity tests: Results across four large-scale job applicant data sets. Journal of Applied Psychology, 83(1), 3542. https://doi.org/10.1037/0021-9010.83.1.35

Ones, D. S., \& Viswesvaran, C. (1998b). The effects of social desirability and faking on personality and integrity assessment for personnel selection. Human Performance, 11(2/3), 245-269. https://doi.org/10.1080/08959285.1998.96680 $\underline{33}$

Ones, D. S., \& Viswesvaran, C. (2001). Integrity tests and other criterion focused occupational personality scales (COPS) used in personnel selection. International Journal of Selection and Assessment, 9, 31-39. https://doi.org/10.1111/1468$\underline{2389.00161}$

Oliver, C., Shafiro, M., Bullard, P., \& Thomas, J. C. (2012). Use of integrity tests may reduce worker's compensation losses. Journal of Business Psychology, 27(1), 115-122. https://doi. org/10.1007/s10869-011-9213-x

Parry, K. W., \& Proctor-Thomson, S. B. (2002). Perceived integrity of transformational leaders in organizational settings. Journal of Business Ethics, 35(2), 75-96. https://doi.org/10.1023/A:1013077109223

Paulhus, D. L. (1984). Two-component models of socially desirable responding. Journal of Personality and Social Psychology, 46(3), 598-609. https://doi.org/10.1037/0022-3514.46.3.598

Paulhus, D. L., \& Williams, K. M. (2002). The Dark Triad of personality: Narcissism, Machiavellianism, and psychopathy. Journal of Research in Personality, 36(6), 556-63. https://doi. org/10.1016/S0092-6566(02)00505-6

Peterson, C., \& Seligman, M. E. P. (2004). Character strengths and virtues: A classification and handbook. New York, Oxford University Press/Washington, DC, APA.

Preiss, M., Krámský, D., \& Příhodová, T. (2014). Morální usuzování a jednání jako součást integrity osobnosti. E-psychologie, 8, 11-28. ISSN 1802-8853.

Preiss, M., \& Mačudová, G. (2013). Dotazník žádoucího stylu odpovídání (BIDR-CZ). [Czech version of Balanced Inventory of Desirable Responding (BIDR-CZ).] Psychiatrie, 17(2), 59-64

Preiss, M., \& Příhodová, T. (2017). Můžeme měřit tendency $\mathrm{k}$ podvádění? Zdravotnictví a medicína, 9, 36-37.

Prottas, D. (2008). Perceived behavioral integrity: Relationships with employee attitudes, well-be- 
ing, and absenteeism. Journal of Business Ethics, 81(2), 313-322. https://doi.org/10.1007/ s10551-007-9496-z

Příhodová, T., Preiss, M., Krámský, D., Stuchlíková, I., Maliňaková, J., Marková, J., \& Příhodová, K. (under review). They break the rules and they are okay with it: Applicability of moral disengagement scale. Manuscript under review at the Polish Psychological Bulletin.

Příhodová, T., Preiss, M., Marková, J., Maliňaková, J., Harsa, P., Prajsová, J., \& Př́íhodová, K. Psychometric analysis of newly developer integrity test for work related assessment - unpublished manuscript

Příhodová, T., Jirsová, T., Preiss, M., \& Juríčková, V. (2017). Integrita a spiritualita - výsledky empirické studie u běžné populace a kontrastních souborů. [Integrity and spirituality - results of empirical study in common population and contrast groups.] Psychiatrie, 21(4), 169-174.

Raisová, M., Příhodová, T., Preiss, M., Maliňaková, J., \& Lumpeová, L. (2019). Vztahy mezi morální integritou osobnosti a invaliditou z príčin duševního onemocnění. [The relationship between personal moral integrity and disability indicated by the mental health issue.] Psychiatrie, 23(1), 15-27.

Raman, P., Sambasivan, M., \& Kumar, N. (2016). Counterproductive work behavior among frontline government employees: Role of personality, emotional intelligence, affectivity, emotional labor, and emotional exhaustion. Journal of Work and Organizational Psychology 32, 25-37, https://doi.org/10.1016/i.rpto.2015.11.002

Robinson, S. L., \& Greenberg, J. (1998). Employees behaving badly: Dimensions, determinants, and dilemmas in the study of workplace deviance. Journal of Organizational Behavior, 5, 1-30.

Robinson, S. J., \& O'Leary-Kelly, A. M. (1998). Monkey see, monkey do: The influence of work groups on the antisocial behavior of employees. Academy of Management Journal, 41, 658-672. https://doi.org/10.5465/256963
Sackett, P. R., \& Harris, M. M. (1984). Honesty testing for personnel selection: A review and critique. Personnel Psychology, 37, 221-245. http://dx.doi. org/10.1111/j.1744-6570.1984.tb01447.x

Schmidt, F. L., \& Hunter, J. E. (1998). The validity and utility of selection methods in personnel psychology: Practical and theoretical implications of 85 years of research findings. Psychological Bulletin, 124(2), 262-274. http://dx.doi. org/10.1037/0033-2909.124.2.262

Sims, R. L. (1993). The relationship between academic dishonesty and unethical business practices. Journal of Education for Business, 68(4), 207-211. https://doi.org/10.1080/08832323.1993.10117614

Soloman, S. R., \& Sawilowsky, S. S. (2009). Impact of rank-based normalizing transformations on the accuracy of test scores. Journal of Modern Applied Statistical Methods, 8(2), 448-462. https://doi.org./10.22237/imasm/1257034080

Sturman, M. C., \& Sherwyn, D. (2007). The truth about integrity tests: The validity and utility of integrity testing for the hospitality industry. Cornell Hospitality Report, 7(15), 6-13.

Šamánková, D., Preiss, M., \& Příhodová, T. (2018). The Contextual Character of Moral Integrity: Transcultural Psychological Applications. Springer.

Škoda, C., Dragomirecká, E., \& Slavíčková, M. (1994). Skrínink skryté psychiatrické nemocnosti. Praha: Psychiatrické centrum Praha.

Van der Linden, D., te Nijenhuis, J., \& Bakker, A. B. (2010). The general factor of personality: A meta-analysis of Big Five intercorrelations and a criterion-related validity study. Journal of Research in Personality, 44, 315-327. https://doi.org/10.1016/i.jrp.2010.03.003

Vrbová, J. (2014). Jak a kdy žáci omlouvají špatné chování ve škole: Role morálního vyvázání se a neutralizace $v$ kontextu školního podvádění starších žáků. Československá Psychologie, 58(5), 455-470.

Williams, B. (1981). Moral Luck: Philosophical Papers 1973-1980. Cambridge: Cambridge University Press. 


\section{Supplement}

Table 1 Descriptive statistics of categorical demographic variables

\begin{tabular}{lcr}
\hline Variable & Value & Frequency (\%) \\
\hline $\mathrm{N}$ & & $121(100)$ \\
Gender & male & $50(41.32)$ \\
& female & $71(58.68)$ \\
Education level & primary & $7(5.78)$ \\
& secondary & $85(70.25)$ \\
& tertiary & $29(23.97)$ \\
\hline
\end{tabular}

Table 2 Descriptive statistics of interval demographic variables

\begin{tabular}{lccc}
\hline & Range & Median & Mean (SD) \\
\hline Age & $20-74$ & 36 & $39.21(14.44)$ \\
Work Years & $.5-56$ & 16 & $18.78(14.39)$ \\
\hline
\end{tabular}

Note. Work Years = number of years employed full time.

Table 3 Scales results of the groups

\begin{tabular}{lccr}
\hline & Range & Median & \multicolumn{1}{c}{ Mean (SD) } \\
\hline Integrity & $69-158$ & 129 & $127.26(15.68)$ \\
SOS-10 & $12-59$ & 46 & $43.81(8.88)$ \\
GHQ & $0-12$ & 0 & $1.2(2.04)$ \\
Moral Identity & $21-60$ & 44 & $43.39(7.49)$ \\
SD3: Machiavellianism & $12-36$ & 22 & $22.09(5.32)$ \\
SD3: Narcissism & $9-33$ & 20 & $20.28(5.31)$ \\
SD3: Psychopathy & $9-40$ & 19 & $19.78(5.89)$ \\
BIDR-CZ: Impression Management & $11-127$ & 68 & $60.80(39.89)$ \\
BIDR-CZ: Self-deception & $12-98$ & 52 & $48.88(26.88)$ \\
BFI-44: Openness to new experiences & $.6-3.8$ & 2.7 & $2.57(.61)$ \\
BFI-44: Conscientiousness & $.2-3.9$ & 2.7 & $2.69(.53)$ \\
BFI-44: Extraversion & $.8-3.9$ & 2.4 & $2.42(.62)$ \\
BFI-44: Agreeableness & $.3-3.8$ & 2.7 & $2.66(.6)$ \\
BFI-44: Neuroticism & $.3-3.8$ & 1.5 & $1.58(.67)$ \\
MD: Overall moral disengagement score & $25-141$ & 59 & $62.5(20.72)$ \\
MD: Moral Justification & $3-21$ & 7 & $8.42(4.46)$ \\
\hline
\end{tabular}


Table 3 continued

\begin{tabular}{lccr}
\hline & Range & Median & Mean (SD) \\
\hline MD: Euphemistic Labelling & $3-19$ & 7 & $7.55(3.58)$ \\
MD: Advantageous Comparison & $3-21$ & 6 & $6.45(3.32)$ \\
MD: Displacement of Responsibility & $3-21$ & 7 & $7.99(4.19)$ \\
MD: Diffusion of Responsibility & $3-19$ & 6 & $6.83(3.69)$ \\
MD: Distortion of Consequences & $3-18$ & 5 & $6.28(2.92)$ \\
MD: Dehumanization & $3-21$ & 11 & $10.91(4.51)$ \\
MD: Attribution of Blame & $3-20$ & 8 & $8.07(3.66)$ \\
CWS: Attitude of Cheating at Work & $21-84$ & 33 & $33.89(9.08)$ \\
CWS: Perception of Cheating at work & $21-65$ & 32 & $31.73(6.75)$ \\
UWBS: Interpersonal scale & $7-41$ & 13 & $14.03(6.74)$ \\
UWBS: Organizational scale & $12-59$ & 20 & $21.82(9.13)$ \\
\hline
\end{tabular}

Note. SOS-10 = Schwartz Outcome Scale - 10; GHQ = General health questionnaire; SD3 = The Short Dark Triad; BIDR-CZ = Balanced inventory of desirable responding; $\mathrm{BFI}-44$ = Big Five Inventory; $\mathrm{MD}=$ Propensity to morally disengage scale; $\mathrm{CWS}=$ Cheating at Work Scale; UWBS = Unethical Work Behavior Scale

Table 4 Correlations with the overall Integrity score

\begin{tabular}{llcc}
\hline Construct & Variable & Spearman $\rho$ & $p$ \\
\hline Moral identity & Moral identity & .11 & .23 \\
Dark Triad & Machiavellianism & -.33 & $<.001$ \\
& Narcissism & -.29 & .001 \\
Social desirability & Pschopathy & -.53 & $<.001$ \\
& Self-deception & .09 & .33 \\
Big Five & Impression management & .55 & $<.001$ \\
& Openness to new experiences & .22 & .02 \\
& Conscientiousness & .31 & $<.001$ \\
& Extraversion & -.03 & .78 \\
Health status & Agreeableness & .31 & $<.001$ \\
& Neuroticism & -.20 & .03 \\
& SOS-10 & .20 & .03 \\
& GHQ & -.15 & .10 \\
\hline
\end{tabular}


Table 4 continued

\begin{tabular}{llcc}
\hline Construct & \multicolumn{1}{c}{ Variable } & Spearman $\rho$ & $p$ \\
\hline Moral disengagement & Moral disengagement - total & -.53 & $<.001$ \\
& Moral Justification & -.54 & $<.001$ \\
& Euphemistic Labelling & -.44 & $<.001$ \\
& Advantageous Comparison & -.41 & $<.001$ \\
& Displacement of Responsibility & -.26 & .005 \\
& Diffusion of Responsibility & -.47 & $<.001$ \\
& Distortion of Consequences & -.49 & $<.001$ \\
& Dehumanization & -.11 & .25 \\
& Attribution of Blame & -.35 & $<.001$ \\
Cheating at work & Attitude scale & -.50 & $<.001$ \\
& Perception scale & -.62 & $<.001$ \\
& Interpersonal scale & -.58 & $<.001$ \\
& Organizational scale & -.57 & $<.001$ \\
\hline
\end{tabular}

Note. SOS-10 = Schwartz Outcome Scale - 10; GHQ = General health questionnaire

Table 6 Characteristics of regression models with Integrity as a predictor

\begin{tabular}{lcccc}
\hline Predicted variable & $\mathrm{F}$ & Adj R $^{2}$ & $\begin{array}{c}\text { Shapiro- } \\
\text { Wilk } p\end{array}$ & $\begin{array}{c}\text { Durbin- } \\
\text { Watson }\end{array}$ \\
\hline Moral disengagement & 42.6 & .26 & $<.001$ & 1.77 \\
Moral disengagement (rank transformed) & 46 & .27 & .75 & 1.78 \\
Cheating at work - Attitude & 42.9 & .26 & $<.001$ & 2.15 \\
Cheating at work - Attitude (rank transformed) & 44.5 & .27 & .35 & 2.04 \\
Cheating at work - Perception & 75.8 & .38 & $<.001$ & 2.13 \\
Cheating at work - Perception (rank transformed) & 71 & .37 & .03 & 2 \\
Work deviance - Interpersonal & 70 & .37 & $<.001$ & 1.86 \\
Work deviance - Interpersonal (rank transformed) & 67.7 & .36 & .17 & 1.86 \\
Work deviance - Organizational & 65.4 & .35 & .012 & 1.77 \\
Work deviance - Organizational (rank transformed) & 60.2 & .33 & .83 & 1.59 \\
\hline Note In all cases, there were 1 and 119 degrees of freedom, and p-values of all models were
\end{tabular}

Note. In all cases, there were 1 and 119 degrees of freedom, and $p$-values of all models were $<.001$. 


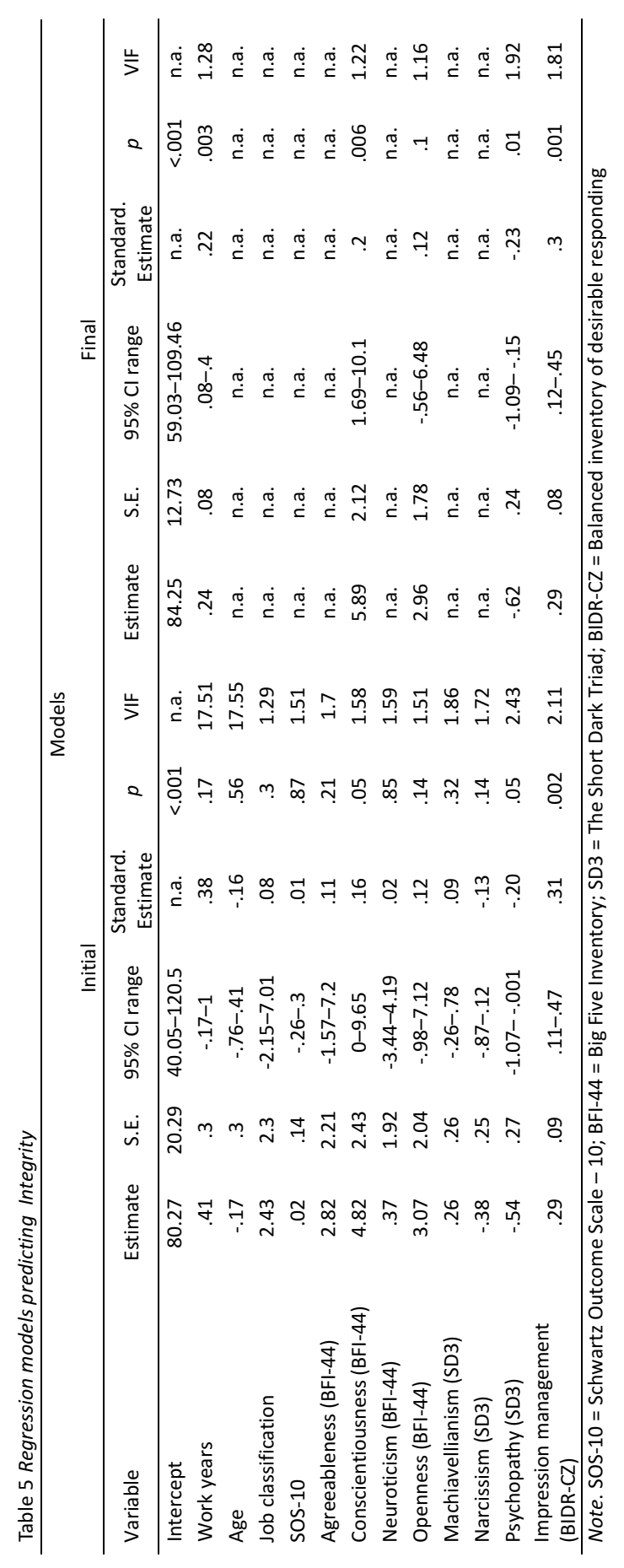

